\title{
Special issue on negotiations: introduction
}

\author{
D. Marc Kilgour ${ }^{1} \cdot$ Rudolf Vetschera $^{2}$ (D)
}

Received: 20 November 2018 / Accepted: 6 December 2018 / Published online: 19 December 2018 (c) The Author(s) 2018

Collective decisions, such as group decisions and negotiations, are a particularly interesting topic for research on decision processes. In contrast to individual decisions, in which a large part of the decision process might take place in the mind of the decision maker and is thus not observable, group decisions and negotiations involve interactions among multiple actors, often making observation and analysis possible. On the other hand, group decision and negotiation usually involves particularly complex decision processes, because the interests of different actors must be considered and in some way accommodated to arrive at a decision that is acceptable to all.

It is, therefore, not surprising that this topic has attracted the interest of researchers from many fields, stretching from game theory, economics, management science, and operations research to social psychology and communications. The Group Decisions and Negotiation conferences, organized by the INFORMS GDN section every year since 2000, are an important forum, where researchers from many disciplines come together to discuss various aspects of this topic from different perspectives.

This Special Issue is the result of a Call for Papers at the annual GDN conference held at Hohenheim University, Stuttgart, in August 2017. It includes some papers presented at the conference, as well as additional papers that were submitted specifically to the Special Issue in response to a subsequent open call. All papers were subjected to the regular review process of EJDP; those that were accepted are published in this issue.

This Special Issue contains five papers that together illustrate very clearly the range of topics and research methods employed in the GDN field. The decision situations covered range from highly cooperative group decisions to severe international conflicts fought using economic sanctions; the methodologies range from game-theoretic analysis to experimental research.

Rudolf Vetschera

rudolf.vetschera@univie.ac.at

D. Marc Kilgour

mkilgour@wlu.ca

1 Wilfrid Laurier University, Waterloo, Canada

2 University of Vienna, Vienna, Austria 
The paper "Application of a hybrid Delphi and aggregation-disaggregation procedure for group decision-making" by A. Bregar has the most cooperative setting. It describes an approach to group decisions that is rooted, on one hand, in the Delphi method and, on the other, in multiattribute decision algorithms, showing the benefits of combining these two approaches.

The next two papers are also based on analytical models, but consider decision situations involving higher levels of conflict. In their paper, "Multiple local optima in Zeuthen-Hicks bargaining: An analysis of different preference models", L. Dias and R. Vetschera take a closer look at the Zeuthen-Hicks model, a well-established model of dynamic bargaining. They analyze whether a main result of that model, the convergence of the process to the Nash bargaining solution, holds even if the parties' preferences fail to meet some standard economic assumptions. The paper "Bargaining over Shares of Uncertain Future Profit” by Y. Gerchak and E. Khmelnitsky also follows an axiomatic approach to bargaining and develops sharing rules applicable to uncertain future profits of a joint venture.

The next two papers in the special issue also consider situations characterized by a strong conflict of interests, but take a more empirical approach. M. Filzmoser and J. Gettinger in "Offer and veto-An experimental comparison of two negotiation procedures" present results of an experimental study testing an innovative approach to negotiations. Rather than proposing solutions they would like to obtain, bargainers in that process specify alternatives which they would not accept as agreements. In their experimental study, the authors show that this process is quite efficient in that it helps parties to achieve better outcomes, although negotiators are less satisfied with the process than in more conventional, offer-based approaches. The final paper of the special issue, "Assessing the Effectiveness of Economic Sanctions" by B. Sabtan, D.M. Kilgour and K. Hipel demonstrates several techniques for the formal analysis of real-world conflicts using the Graph Model for Conflict Resolution.

Our hopes for this Special Issue are twofold. We hope that the papers collected here will attract more researchers interested in decision processes to study problems related to group decision and negotiations. At the same time, we hope that this Special Issue will help to establish EJDP as an additional publication outlet for the GDN community.

Finally, we would like to thank the Editor in Chief of EJDP, Vincent Mousseau, for the opportunity to edit this Special Issue and the excellent collaboration in preparing it, and the local organizer and Program Co-Chair of GDN 2017, Mareike Schoop, for her support in soliciting contributions to the Special Issue at the conference.

Acknowledgements Open access funding provided by University of Vienna.

Open Access This article is distributed under the terms of the Creative Commons Attribution 4.0 International License (http://creativecommons.org/licenses/by/4.0/), which permits unrestricted use, distribution, and reproduction in any medium, provided you give appropriate credit to the original author(s) and the source, provide a link to the Creative Commons license, and indicate if changes were made. 